\title{
Architectural Insight into A.I based Inhaler System for Respiratory Precision
}

\author{
Sadique Shaikh ${ }^{1 *}$, Shaikh Tarique $\mathrm{Aziz}^{2}$ and Minaz Khan ${ }^{3}$ \\ ${ }^{1}$ ISTM, India \\ ${ }^{2}$ R.D Memorial Medical College, India
}

${ }^{3}$ Ashwi Medical College, India

*Corresponding author: Sadique Shaikh, ISTM, Mumbai, M.S, India

\section{ARTICLE INFO}

Received: 慧 September 26, 2019

Published: 慧 October 03, 2019

Citation: Sadique S, Shaikh T A, Minaz Khan. Architectural Insight into A.I based

\section{ABSTRACT}

Present piece of idea exhibits to divert attention towards automated high precision Life Support System (LSS) instead of manual one using medical intelligence devices while treating and diagnosis to the patient, where Ventilator, inhaler and respiratory control is most important factor during operation, surgeries and in other likewise medical emergency situations to maintain proper saturation in patient lungs to sustain their lives. This work gives idea, how we can design A.I based Inhaler System for the same.
\end{abstract} Inhaler System for Respiratory Precision. Biomed J Sci \& Tech Res 21(4)-2019. BJSTR. MS.ID.003646.
Keyword: A.I based Inhaler System; A.I based Life-Support System; Medical Robotics; Surgical Robots

\section{Modeling}

The below model depicted the successful engineering how one can design and implement A.I based Inhaler System for Respiratory precision to maintain saturation of human breathing system, we can even labeled the system as Artificial Intelligence based lungs or Lungs Support System or Oxygen Support System or Breath Support System but purpose remains same. Patient respiratory sensed and input parameters send to Saturation Measurement Unit which must be highly calibrated and compare Measured saturation with Standard Saturation to find deviation for error detection and correction from where physical quantity fed to A.I based processing

\& controlling chamber with time control for inhalation decision support with all expert analysis and diagnosis which generate electronic respiratory report with necessary timing, processing and control signals to get follow further send to A.I based Inhaler System to decide and fixed precision parameters for respiratory. This report A.I based processing and control chamber generate on the basis of actual saturation and required saturation facts and figures further passed to Respiratory Correction for Proper Saturation Unit which is cascaded with Oxygen Level Supplier and Maintainer and work integrated. Finally stable inhalation feedback to patient for life survival in critical condition (Figure 1) [1-6].

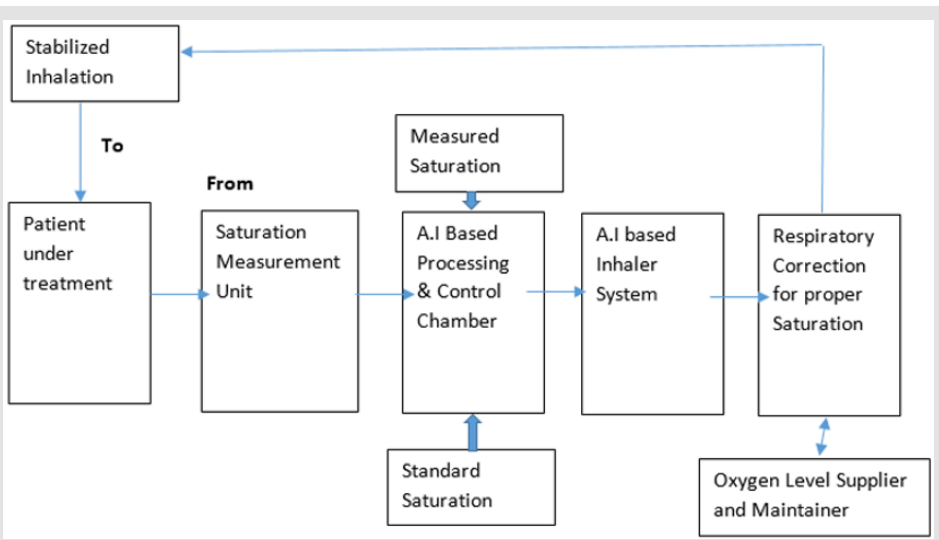

Figure 1. 


\section{Conclusion}

This piece of research gives you idea, how to engineer and implement precise artificial Intelligence based Inhaler System which is one of the most promising, needful and social welfare requirement to save patients' lives with excellent Life Support System (LSS).

\section{References}

1. NSF/EC Understanding on Co-operation in Information Technologies -Strategic Research Workshops IST-1999-12077.

2. Md. Sadique Shaikh (2013) Analysis and modeling of Strong AI to engineer BIONIC brain for humanoid robotics application. American

\section{ISSN: 2574-1241}

DOI: 10.26717/BJSTR.2019.21.003646

Sadique Shaikh. Biomed J Sci \& Tech Res

cC) This work is licensed under Creative

Submission Link: https://biomedres.us/submit-manuscript.php
Journal of Embedded System and Applications, Published by Science Publishing Group 1(2): 27-36.

3. Sadique Shaikh (2017) Ultra Artificial Intelligence (UAI): Redefing Al fir New Research Dimension. Advanced Robotics \& Automation (ARA), OMICS International, London 6(2): 1-3.

4. Sadique Shaikh (2017) Fundamental Engineering for Brain-Computer Interfacing (BCI): Initiative for Neuron-Command Operating Devices. Computational Biology and Bioinformatics (CBB). SciencePG 5(4): 5056.

5. Sadique Shaikh (2018) Defining ultra-artificial intelligence (UAI) implementation using bionic (biological-like-electronics) brain engineering insight. MOJ App Bio Biomech 2(2): 127-128.

6. Sadique Shaikh Md (2008) Insight Artificial to Cyborg Intelligence Modeling. Arch Ind Engg1(1): 1- 5.

$\begin{array}{ll}\text { BIOMEDICAL } & \text { Assets of Publishing with us } \\ \text { RESEARCHES } & \text { - Global archiving of articles } \\ & \text { - Immediate, unrestricted online access } \\ & \text { - Rigorous Peer Review Process } \\ \end{array}$

